\title{
Growth and Nutrition Disorders in Children with Cerebral Palsy
}

\author{
Michelle N. Kuperminc and Richard D. Stevenson ${ }^{*}$ \\ Department of Pediatrics, University of Virginia, Charlottesville, Virginia
}

\begin{abstract}
Growth and nutrition disorders are common secondary health conditions in children with cerebral palsy (CP). Poor growth and malnutrition in CP merit study because of their impact on health, including psychological and physiological function, healthcare utilization, societal participation, motor function, and survival. Understanding the etiology of poor growth has led to a variety of interventions to improve growth. One of the major causes of poor growth, malnutrition, is the beststudied contributor to poor growth; scientific evidence regarding malnutrition has contributed to improvements in clinical management and, in turn, survival over the last 20 years. Increased recognition and understanding of neurological, endocrinological, and environmental factors have begun to shape care for children with $\mathrm{CP}$, as well. The investigation of these factors relies on advances made in the assessment methods available to address the challenges inherent in measuring growth in children with CP. Descriptive growth charts and norms of body composition provide information that may help clinicians to interpret growth and intervene to improve growth and nutrition in children with CP. Linking growth to measures of health will be necessary to develop growth standards for children with $\mathrm{CP}$ in order to optimize health and well-being.
\end{abstract}

\section{Keywords}

growth; nutrition; cerebral palsy

\section{INTRODUCTION}

Cerebral palsy is the most common physical disability in children and affects $3.6 / 1,000$ children [Yeargin-Allsop et al., 2008]. According to definition, "Cerebral palsy (CP) describes a group of permanent disorders of the development of movement and posture, causing activity limitation, that are attributed to nonprogressive disturbances that occurred in the developing fetal or infant brain. The motor disorders of CP are often accompanied by disturbances of sensation, perception, cognition, communication, and behavior, by epilepsy, and by secondary musculoskeletal problems" [Rosenbaum et al., 2007]. Although the primary impairment in CP is in motor function, growth and nutrition disorders are common. These growth differences may be present among all children with CP [Stallings et al., 1993a,b]; however, they are more common and prominent with increasing severity of motor impairments [Stevenson et al., 2006b; Day et al., 2007].

Physical growth is a fundamental measure of health and well-being in children, and abnormal growth may be considered a sign of disruption in a child's nutrition, environment, or health. Even under seemingly "good" conditions (appropriate environment and regular medical attention), children with CP grow more slowly than children without chronic health conditions 
[Samson-Fang and Stevenson, 1998], and the differences in growth increase with increasing age [Stevenson et al., 1994]. Diminished body fat and overall growth in children with CP have been associated with increased health care utilization and decreased societal participation [Samson-Fang et al., 2002; Stevenson et al., 2006b]; thus, understanding the growth patterns in this population is important in promoting "health" in all its dimensions.

\section{BACKGROUND AND SIGNIFICANCE}

One of the goals of the U.S. Department of Health and Human Services, as stated in Healthy People 2010, is to promote the health of people with disabilities, prevent secondary conditions, and eliminate disparities between people with and without disabilities [Centers for Disease Control and Prevention et al., 1999]. In part, this goal is necessary, because an under-emphasis of health promotion and disease prevention activities targeting people with disabilities has increased the occurrence of secondary health conditions. These secondary health conditions can have a profound impact on general health and well-being, or health-related quality of life.

Poor growth and malnutrition can be conceptualized as important secondary health conditions that impact the global health and well-being of children with CP and their families. Although the medical literature supports the premise that children with CP grow poorly, growth may not be the most important outcome. What may be more important is that the poor growth of children with CP may be due to factors (e.g., malnutrition, abnormal endocrine function, decreased weight bearing) that have other negative health consequences that pose a significant burden to families and to society. Investigators have studied the relationship of poor growth and malnutrition with general health and well-being. The association of impaired growth with changes in healthcare utilization, societal participation, motor function, life expectancy, and bone health highlights the concerns about poor growth and nutritionin children with $\mathrm{CP}$.

\section{Impact of Nutrition on Well-Being}

Since nutrition is an important area of the management of children with $\mathrm{CP}$, it is imperative to clarify the role of nutrition in maintaining health and well-being. Evidence documenting the effects of poor growth and malnutrition on the health of children with $\mathrm{CP}$ is limited, although much of the research done on adults and children without disabilities is applicable to this population. The ill effects of malnutrition on physiology, motor function, neurological and psychological function are wide ranging and may be particularly devastating during early development. Diminished muscle strength leads to impairment in motor function as well as weakness of respiratory musculature, with resultant impaired cough and predisposition to pneumonia [Kelly et al., 1984]. Malnutrition results in increased circulation times and diminished cardiac work capacity, and a predisposition to congestive heart failure when under cardio-respiratory stress [Viart, 1977, 1978]. Malnutrition leads to diminished immune function [Chandra and Kumari, 1994], causing increased susceptibility to infection. Neurological consequences include diminished cerebral growth, delayed cognitive development, and abnormal behavior [Engsner et al., 1974; Grantham-Mcgregor et al., 1991; Viteri, 1991; Liu et al., 2003; Smart, 1993]. Further, undernourished children show lower levels of exploratory activity and attachment behavior that may affect social-emotional development [Graves, 1978]. Irritability and decreased activity have been described clinically in undernourished children [Viteri, 1991] and documented in animal models of malnutrition [Graves, 1978]. Malnutrition decreases the energy available for discretionary activity, which decreases social interaction, increases apathy, and negatively affects learning and quality of life [Lewis et al., 1994]. These characteristics may affect a child's ability to participate in play, school, or rehabilitation.

In children with $\mathrm{CP}$, malnutrition has been shown to increase the severity of gastroesophageal reflux, and nutritional rehabilitation has been shown to lessen the symptoms associated with 
gastroesophageal reflux [Lewis et al., 1994]. Malnutrition impairs wound healing and immunity, which increases the risk of postoperative complications following surgery for fundoplication [Weber, 1995] and scoliosis repair [Jevsevar and Karlin, 1993].

\section{Impact of Growth on Healthcare Utilization and Participation}

The effect of overall growth on markers of health, specifically healthcare utilization and societal participation, is an active area of investigation. Samson-Fang [Samson-Fang et al., 2002] evaluated the relationship between nutritional status, as determined by body composition measurements, and markers of general health, health care utilization, and social participation. There was a significant correlation between nutritional status and health status. Children with a triceps skinfold below the fifth percentile tended to have lower global health scores on the Child Health Questionnaire (CHQ), although this relationship did not reach statistical significance. However, children with arm-muscle area (a measure of lean mass) below the fifth percentile had significantly lower global health $z$-scores (CHQ) than children with normal armmuscle area. In addition, triceps skinfold $z$-score correlated significantly with child healthcare utilization, child participation in usual activities, and family activities. Each standard deviation increase in triceps skinfold was associated with a $20 \%$ reduction in doctor visits, a $50 \%$ reduction in hospitalizations, a $22 \%$ reduction in days missed from school, and a $33 \%$ reduction in missed activities for the family over the preceding 4-8 weeks. There were very similar (and statistically significant) relationships between these same outcome measures and other nutritional indicators (arm-muscle area, arm-fat area, and subscapular skinfold), but not stature [Samson-Fang et al., 2002]. This study was the first to document a link between nutritional status, as defined by anthropometry, and health care utilization and participation.

Stevenson et al., in a multicenter study of 273 children with moderate to severe CP, described growth patterns and their relationship to health and societal participation. They created growth curves for weight, knee height, upper arm length, mid upper arm-muscle area, triceps skinfold, and subscapular skinfold. Cluster analysis identified three clusters of subjects based on average $z$-scores for each of these areas. Cluster analysis was utilized in an attempt to integrate multiple aspects of growth (overall body mass, fat mass, lean tissue mass, linear growth) into a single variable. The subjects with the best growth overall, as defined by their growth cluster, had fewer days of health care use and more days of participation in their usual activities. The growth curves created as part of this study were not presented as standards for this population, but rather as descriptive of a heterogeneous population that may include varying levels of acute and chronic malnutrition and endocrine abnormalities. Further prospective study is needed to verify that the "bigger" kids are, in fact, "better" in terms of health and well-being, before using these growth curves to guide clinical decisions [Stevenson et al., 2006b].

\section{Impact of Growth on Motor Function}

Since growth and malnutrition affect muscle function and energy, it seems reasonable that improved nutrition and growth might improve motor function in children with CP. This is particularly difficult to assess, because the smallest children with the poorest growth are often those with the most severe motor impairments. Gains in muscle strength in this group might not improve ability to move independently but might improve health (i.e., improved ability to cough, thus preventing pneumonia) in ways not measurable by current motor classification measures. Campanozzi et al. examined the impact of malnutrition and nutritional rehabilitation on gastrointestinal disorders and motor function in children with CP. They studied a sample of 21 children with $\mathrm{CP}$ and severe mental retardation. Fourteen of twenty-one children were judged malnourished based on body fat mass (anthropometry) $<80 \%$ of ideal or body mass index $(\mathrm{BMI})<$ fifth percentile. Motor function was evaluated using the Gross Motor Function Measure. All 14 of those children underwent 6 months of nutritional rehabilitation. Nine out of fourteen also were treated for gastroesophageal reflux disease. There were significant 
improvements, not only in weight, fat stores, and lean body mass, but also in starting and final GMFM. Counter to prior evidence [Lewis et al., 1994], these investigators found that treatment of malnutrition did not improve gastroesophageal reflux disease [Campanozzi et al., 2007]. Further research using stable measures of motor function and reliable measures of growth are needed to document the effects of nutrition and growth on motor function.

\section{Growth and Survival}

There is long-standing interest in life expectancy in CP, especially since some individuals with $\mathrm{CP}$ have a shortened lifespan. Strauss et al. performed a 20-year retrospective study of survival in 47,259 (28,513 were children aged 4-14) individuals with CP in California. Subjects were analyzed by severity, gender, mode of feeding (tube feeding, self feeding, oral feeding by others), and mobility. The investigators found that children with CP and severe disabilities have had increased life expectancy over the past 20 years. Although the data do not demonstrate causality, a variety of factors, including medical treatment, social/community supports, and nutritional management may be responsible for this improvement. Specifically, the mortality rates in the individuals with the most severe disabilities has decreased by $50 \%$ over this 20 year period, while gastrostomy placement has increased markedly [Strauss et al., 2007].

\section{Growth and Bone Health}

Bone growth, assessed in part by bone mineral density (BMD), is another important aspect of growth in children with CP. In addition to poor linear growth, children with moderate to severe $\mathrm{CP}$ often sustain painful, pathological fractures due to poor mineralization of bone [Stevenson et al., 2006a]. Thus, bone growth and bone density are highly relevant to overall linear growth, nutritional health, and health-related quality of life. Henderson et al. studied the impact of growth on bone density and have shown in several observational studies that among the factors affecting bone density are weight and nutritional status [Henderson et al., 2002a, 2004, 2005]. Fractures are common among children [Henderson et al., 2002a; Stevenson et al., 2006a] and adults [King et al., 2003] with moderate-severe CP. Henderson showed that $26 \%$ of children over 10 years had already sustained at least one fracture [Henderson et al., 2002a], and Stevenson showed a fracture rate of $4 \%$ per year [Stevenson et al., 2006a]. Advancing age, greater motor impairment, poor nutritional status (as measured by skinfolds), and oral-motor dysfunction (difficulty feeding) were independent contributors to the variance in bone density [Henderson et al., 2002a]. Risk factors for fracture were higher body fat, gastrostomy use, and previous fracture [Stevenson et al., 2006a]. Optimizing bone growth in $\mathrm{CP}$ is an important aspect of improving health.

\section{ETIOLOGY OF POOR GROWTH}

Abnormalities in growth and body composition, once thought to be intrinsic to CP, result from a variety of causes some of which might be altered to improve growth. Malnutrition (predominantly protein calorie malnutrition that is usually accompanied by micronutrient malnutrition) [Stallings et al., 1993b; Stevenson et al., 1994], endocrine dysfunction [Stevenson et al., 1995; Coniglio et al., 1996], and a variety of other factors, such as mechanical forces and neurological differences [Stevenson et al., 1995; Henderson et al., 2007] contribute to this poor growth. These factors appear to act synergistically to affect growth in every dimension including diminished linear growth and weight gain, and abnormal body composition (decreased muscle mass, fat mass, and bone density).

\section{Malnutrition}

A significant contributor to poor-growth children with $\mathrm{CP}$ is poor nutritional status. Typically, malnutrition occurs when a child is unable to take in necessary nutrients (due to difficulty feeding or scarcity) or when the needs of the child (because of illness or increased metabolic 
rate) exceed what she can consume. Malnutrition in children with $\mathrm{CP}$ is often caused by poor oral-motor function, which impairs the child's ability to safely consume calories and nutrients necessary to support growth [Fung et al., 2002]. One theory is that children with CP have increased metabolic needs, due to hypertonia or movement disorders [Lundberg, 1976], compared to typical children. In support of this theory, McCoy et al. showed significant weight gain in children with hypertonia during treatment with intrathecal baclofen. The authors speculate that decreased spasticity and energy expenditure led to improved growth [McCoy et al., 2006]. However, a study by Stallings et al. supported earlier findings that individuals with CP have low resting energy expenditure [Bandini et al., 1991], suggesting that children with $\mathrm{CP}$ have decreased metabolic needs. The investigators measured resting energy expenditure by indirect calorimetry and total energy expenditure by the doubly labeled water method. They compared 61 children with $\mathrm{CP}$ (all participated in anthropometry, 32 in total energy expenditure testing and 37 in resting energy expenditure testing) with a control cohort of 32 typically growing children, suggesting that the nonbasal energy expenditures for children with spastic quadriplegic CP were actually low and that inadequate intake rather than excessive metabolic need leads to malnutrition in this population. In fact, those who had low fat stores had even lower resting energy expenditure, likely due to a metabolic adaptation to chronic malnutrition [Stallings et al., 1996].

Regardless of the degree of motor impairment, data suggest that all children with CP are at risk for malnutrition. In a study of children with hemiplegia or diplegia (milder motor impairment), linear growth was reduced and $30 \%$ of the sample were undernourished [Stallings et al., 1993a]. In a study of 142 children with spastic quadriplegia (more severe motor impairment), Stallings et al. showed that linear growth, body weight and measures of body fat were all reduced [Stallings et al., 1993b, 1995], and that nutritional status explained 10-15\% of the variation in linear growth [Stallings et al., 1993b]. Overall, the CP group had decreased growth and abnormal body composition compared with controls. A subset of children with CP who had normal fat stores were not significantly different from controls in measures of body composition, but still had diminished linear growth [Stallings et al., 1996]. This suggests that nutrition has a greater effect on weight and measures of body fat than on linear growth.

Stevenson and colleagues completed a series of studies to further investigate the etiology of growth in children with CP. In a cross-sectional survey of 171 children [Stevenson et al., 1994], 38\% were below the third percentile for height, $38 \%$ were below the third percentile for weight, and $30 \%$ of children had a triceps skinfold below the third percentile. Linear growth correlated positively with weight and head circumference, but negatively with age and markers of functional severity. Weight $z$-score and age contributed significantly to the variance in stature. These authors concluded that nutritional status was a major correlate of growth. However, their data showed that linear growth $z$-score worsened with age, independent of nutritional status, suggesting that other factors also influence growth. Their cross-sectional data showed that older children were further from normal than younger children. This divergence from the norm and worsening $z$-scores with age suggested the possibility of endocrinopathy [Stevenson et al., 1994].

Samson-Fang and Stevenson completed a longitudinal study of a convenience sample of 82 children with CP (53\% boys, $80 \%$ Caucasian) under 10 years of age, who were measured on two occasions over a minimum interval of 0.8 years. Mean growth velocity $z$-score was -1.3 . Boys grew more slowly than girls. Children at nutritional risk (triceps skinfold $<5 \%$ ) grew poorly compared to those with adequate triceps skinfold thickness. Thus, children with $\mathrm{CP}$ grew more slowly than expected compared to age and gender-based standards, and nutritional status contributed to slow growth [Samson-Fang and Stevenson, 1998]. In summary, children with CP grow poorly, and malnutrition appears to be a major contributing cause, though by no means the only cause. 


\section{Environment}

The impact of environmental factors on growth are recognized, but poorly understood. Henderson et al. published a study comparing growth in 75 children with moderate to severe $\mathrm{CP}$ living in a residential care facilities compared with 250 children living at home. They found that the children living in residential care facilities had significantly greater weight, height, skinfold thicknesses, and midarm muscle area $z$-scores, even when controlling for age, severity of motor impairment. Although the data do not demonstrate causality, they suggest that some factors in the environment, whether strict adherence to feeding schedule, intensive medical treatment or other factors, affect growth [Henderson et al., 2007].

\section{Endocrine Factors}

Because patterns of abnormal growth in prior studies of children with $\mathrm{CP}$ suggested possible endocrinopathy, Coniglio et al. investigated patterns of growth hormone (GH) secretion, in 10 children with $\mathrm{CP}$ and growth failure. Six of the children had subnormal GH secretion both spontaneously and in response to pharmacological stimulation (Arginine/L-DOPA), consistent with GH deficiency. The hormonal patterns were not consistent with that reported in malnutrition. The authors concluded that abnormalities of GH secretion might play a role in the growth failure of some children with CP [Coniglio et al., 1996].

As children with CP grow older, their growth diverges further from that of typically growing children [Stevenson et al., 1994]. In published descriptive growth charts of children with CP [Stevenson et al., 2006b; Day et al., 2007], children with moderate to severe CP seem to lack a dramatic pubertal growth spurt. Worley et al. showed that although children with moderate to severe CP may experience adrenarche earlier than typical children, they enter puberty later and their puberty lasts longer [Worley et al., 2002]. Since the pubertal growth spurt accounts for a large amount of adult height, hormonal differences during puberty in children with $\mathrm{CP}$ may be an important factor in limiting overall growth. A longitudinal study by Kuperminc et al. suggests that pubertal girls with $\mathrm{CP}$, even when adjusting for nutritional status have decreased IGF-1 and GH. This low IGF-1 and GH correlated with diminished linear growth [Kuperminc, unpublished data, 2007]. The etiology of endocrine abnormalities remains unclear; further study of hormonal influences on puberty in children with $\mathrm{CP}$ is necessary.

Although most typical children can be assessed using only weight and height measures, children with CP often need measures of body composition in order to assess nutritional status.

\section{Non-Nutritional, Nonendocrine Factors}

To investigate the effects of other non-nutritional factors on growth, Roberts and Stevenson studied 20 children with hemiplegia, normal nutritional status, and normal stature. All measures of breadth, circumference, and length were smaller on the affected side compared to the unaffected side. The skeletal age of the affected side was less than that of the unaffected side in all subjects. The magnitude of differences in hand length and skeletal age correlated with the functional severity. The authors concluded that non-nutritional factors related to disease severity had a significant effect on growth and skeletal maturation. Because these hemiplegic children had normal stature, these nonnutritional factors did not appear to be endocrine [Roberts et al., 1994; Stevenson et al., 1995]. The nature of these other factors that impact on growth remains unclear. 


\section{ASSESSMENT OF GROWTH}

Challenges of growth surveillance in children with $\mathrm{CP}$ arise for two main reasons. First, it is difficult to obtain reliable measures of growth, particularly linear growth or stature. Second, generally accepted reference standards may not be appropriate, such that interpretation of growth data is difficult. Although most typical children can be assessed using only weight and height measures, children with $\mathrm{CP}$ often need measures of body composition in order to assess nutritional status.

\section{History and Physical Exam}

History and physical examination form the basis for any pediatric visit and in children with $\mathrm{CP}$ allow identification of factors that contribute to poor growth. History should focus on feeding difficulties, positioning problems, or increased energy needs that may be amenable to intervention. Dietary history is helpful in obtaining qualitative rather than quantitative data regarding intake. Stallings and colleagues showed that quantitative assessment of oral intake in children with quadriplegic CP over-estimated the amount actually ingested by $44-54 \%$ (as measured by total energy expenditure by doubly labeled water techniques) [Stallings et al., 1996]. A complete physical examination may yield important information about specific causes of growth abnormalities. Attention to nails and skin abnormalities may suggest specific micronutrient deficiencies [Meyer-Heim and Khan, 2004] Pressure ulcers may be signs of malnutrition a well as causes of increased metabolic demand.

\section{Weight}

Measurement of weight is straightforward using standard infant and pediatric/adult scales. Larger children with disabilities may be difficult to weigh if they are too large for the infant scale and are unable to stand independently for a standard scale. A bed scale, as used in most hospitals and nursing homes, or a chair scale, provides a good alternative for these children. In the absence of specialized equipment, a reliable method for many children is to weigh the child together with a caregiver, and then subtract the weight of the caregiver.

\section{Stature}

Reliable measures of height or length in children with $\mathrm{CP}$ are often impossible to obtain due to fixed joint contractures, involuntary muscle spasms, and poor cooperation due to associated cognitive deficits [Tobis et al., 1961; Spender et al., 1989]. Alternatives to height or length, namely the segmental measures of upper arm length and lower leg length and knee height, have been investigated for use in children with CP [Spender et al., 1989] and have been recommended for children and adults with various disabilities [Stevenson, 1996]. Formulas for estimating stature from the segmental measures of upper arm length, tibial length, and knee height have been developed for children with CP [Stevenson, 1995], and children and adults with disabilities [Chumlea et al., 1994].

\section{Nutritional Status and Body Composition}

Body composition refers to quantifiable components of the body including fat, water, protein, and bone. Methods to measure these components directly include underwater weighing for body density, doubly labeled water, and Dual X-Ray Absorptiometry (DXA). Whole body DXA has become the "gold standard" for the measurement of body composition. DXA has been validated for use in children with altered body posture, like those with CP [Henderson et al., 2001]. DXA and other direct measures are not, however, readily available to clinicians, so indirect measures including anthropometry and bioelectrical impedance may be used. 
Triceps and subscapular skinfolds and arm-fat area provide useful information regarding fat stores [Patrick and Gisel, 1990]. Standard techniques for measuring skinfolds are well established and can be used for children with disabilities [Lohman et al., 1988]. Equations for calculation of body fat from skin fold thickness [Slaughter et al., 1988] are available although unvalidated in this population, as are normative values for skinfold thickness [Frisancho, 1981]. The single best screening tool for malnutrition in children with CP is the triceps skinfold [Samson-Fang and Stevenson, 2000].

Muscle mass can be estimated using midarm circumference and triceps skinfolds measurements in standard equations. Midarm muscle area can be computed from these measurements using standard equations, and $z$-scores can then be determined from reference data [Frisancho, 1981]. These calculations have not been validated specifically in children with $\mathrm{CP}$ but may underestimate muscle mass since the constant used to estimate bone mass is based on normally growing children who have more bone mass than children with $\mathrm{CP}$.

Few studies compare estimates of body composition with more complex measures. Liu et al. compared the measurement of body composition using bioelectrical impedance, anthropometry (the Slaughter equations), and DXA in a group of eight children with CP. They found that correlation coefficients for determination of fat-free mass were excellent ( 0.9$)$ for all methods but only moderate for fat mass and percent body fat (range: $0.4-0.8$ ). Skin folds were better predictors of percent body fat, while bioelectrical impedance was a better predictor for fat mass. They did not find a systematic difference for variation among methods to estimate body composition [Liu et al., 2005].

In contrast, Stallings et al. found a systematic difference in variation in comparing the use of doubly labeled water to measure body composition (specifically fat mass) with anthropometric measures to estimate body composition. In this study, skinfolds underestimated fat mass and fat-free mass determined by doubly labeled water for both control children and children with CP. The Slaughter equations yielded a value that systematically underestimated fat mass from doubly labeled water by $1.3 \mathrm{~kg}$ in both subjects with spastic quadriplegic $\mathrm{CP}$ and control subjects [Stallings et al., 1995]. Further research will be necessary to validate the use of these equations for use in children with $\mathrm{CP}$ or to create new "CP specific" equations.

\section{Bone}

As with physical anthropometry, the assessment of bone density in this population has presented some challenges related to musculoskeletal deformity. Henderson and colleagues utilized DXA to measure bone density in 139 children and adolescents with CP of wide ranging severity, including 37 nonambulatory quadriplegics. DXA is typically used to measure bone density at the lumbar spine and at the hip. In Henderson's study, however, bone density assessment was often limited to the lumbar spine because hip flexion contractures and/or previous hip surgery prevented reliable measurement in the proximal femurs [Henderson et al., 1995]. This proved to be an important limitation because Henderson subsequently found that bone density of the lumbar spine was not predictive of fracture risk [Henderson, 1997a]. This is likely explained by the lack of correlation between bone density measures in the lumbar spine and the lower limbs [Henderson, 1997b], while fractures occur primarily in the lower limbs. To address this measurement problem, Harcke and colleagues developed a new technique using DEXA to measure bone density in the distal femur, projected in the lateral plane. This has been successful in children with CP, even those with significant contractures [Harcke et al., 1998]. Henderson and Harcke also obtained the necessary normal reference data $(n=256)$ so that bone density measures in the new distal femur site could be interpreted relative to age-matched normal children [Henderson et al., 2002c]. 
Utilizing the distal femur technique, Henderson has documented that BMD is often low in moderate-severe children with CP and that BMD $z$-scores correlate with severity of involvement and age [Henderson et al., 2004]. As with linear growth, BMD $z$-scores deviate further from the norm with age. However, a longitudinal study of bone density in children and adolescents with CP showed that BMD increased steadily with age, but that BMD $z$-scores decreased with age [Henderson et al., 2005].

\section{Biochemical Evaluation}

Select laboratory studies may be helpful in guiding nutritional management of children with $\mathrm{CP}$, although there is little evidence to support routine biochemical assessment of nutritional status or of micronutrients (vitamins and minerals). Serum albumin and prealbumin have not been found to be helpful in predicting nutritional status in children with CP [Lark et al., 2005]. Henderson et al. studied bone density and metabolism in a group of children with moderate to severe $\mathrm{CP}$ and found that, many children had decreased levels of hydroxy vitamin D [Henderson et al., 2002a].

Children with CP and epilepsy who are treated with valproate or a ketogenic diet can develop secondary carnitine deficiency, which may increase the risk of valproate induced hepatotoxicity. An advisory committee of pediatric neurologists recommended supplementation of carnitine in children taking valproate [De Vivo et al., 1998], but there are no guidelines for assessment of carnitine levels in children with CP.

A study by Hillesund et al. offers evidence to support the need for evaluation of micronutrients. The investigators estimated intake (by diet history) and also measured micronutrient concentrations in a heterogeneous group of 36 children with $\mathrm{CP}$. All children were noted to have deficiencies in zinc, selenium, iron, folate, vitamin E, vitamin B6, and vitamin B12. Children receiving enteral (orally or by gastrostomy) nutritional supplements $(n=15)$ had better levels of all micronutrients than those not receiving nutritional supplements. Although the authors conclude that children with CP should undergo micronutrient evaluation [Hillesund et al., 2007], further studies are needed to develop evidence-based recommendations for the timing and depth of evaluations.

In the absence of evidence, physical findings and clinical judgment continue to dictate the need for biochemical evaluation. In practice, it seems prudent to screen for abnormalities periodically, particularly in severely impaired or chronically ill children. Vitamin D studies, in children at risk for vitamin D deficiency (e.g., dark skin, limited exposure to sunlight, chronic use of antiepileptic agents) should be considered at yearly visits. Complete blood count and iron studies should be considered to identify iron deficiency and anemia. Complete blood chemistries should be considered to identify underlying abnormalities in liver, kidney, and bone turnover.

\section{INTERPRETATION OF GROWTH MEASUREMENTS}

Even when reliable anthropometric measures are obtained in children with disabilities, the interpretation of the data and the diagnosis of malnutrition or growth failure are often unclear. Use of normal growth charts, particularly the weight-for-height or BMI norms, in children with less muscle mass and bone density due to physical inactivity may not be appropriate [Patrick and Gisel, 1990; Samson-Fang and Stevenson, 1998]. Weight for height, or a similar indicator of nutrition such as BMI, typically used as a screening tool for malnutrition, is a poor predictor of low fat stores in children with CP [Samson-Fang and Stevenson, 2000] when standard (National Center for Health Statistics) growth charts are utilized. 
Diagnosis-specific growth curves have been developed for other conditions, such as Down syndrome and Turner syndrome [Cronk et al., 1988; Rongen-Westerlaken et al., 1997; Myrelid et al., 2002, Styles et al., 2002], where genetic abnormality directly influences stature.

Reference growth curves for children with CP may be helpful to clinicians and beneficial to children; however, any representative sample of children with moderate or severe $\mathrm{CP}$ is heterogeneous and likely to include many children with differing degrees of acute and chronic malnutrition and, possibly, GH deficiency [Stallings et al., 1993b; Coniglio et al., 1996]. Furthermore, growth charts such as those created by Krick [Krick et al., 1996] using unreliable methods of measurement are of unknown validity and, therefore, questionable utility.

Currently, there is little data to guide clinicians regarding what constitutes ideal, or even adequate, growth and nutritional status in children with CP.

Recent charts by Day et al. and Stevenson et al. improve on early attempts at creating growth charts. Day et al. published a report on the development of reference growth curves for children with CP based on data from the California registry for children with disabilities [Day et al., 2007]. The major strengths of these reference curves are the large number of children included and the creation of separate curves based on the degree of functional severity. The primary weakness of the report is that the measures of stature utilized (height or length) are of unknown reliability in this population, particularly in the more severely impaired children. Nevertheless, these reference charts can be helpful to clinicians who may compare their patients' growth to that of another group of children with CP. Stevenson et al. published growth charts describing growth patterns of a smaller group $(n=273)$ of children with CP that improves on earlier models in two major ways: the use of reliable measures of linear growth, and cluster analysis showing a relationship to healthcare utilization and societal participation relates growth to markers of overall health. However, these charts are not yet available in a form that clinicians might utilize [Stevenson et al., 2006b].

Potentially a "prescriptive" growth curve with statistically and clinically significant links between body size and proportions and health and societal participation outcomes would help guide clinical decisions. Some precedent for this type of growth chart now exists, developed and published recently by the World Health Organization (WHO). The WHO Multicentre Growth Reference Study was purposely designed to produce a standard, rather than a reference, for growth. The growth charts were created through a longitudinal study of a cohort of children in six different countries (with built-in ethnic and cultural variability), raised under "ideal" health conditions likely to favor achievement of genetic growth potentials [WHO Multicentre Growth Reference Study Group, 2006]. In this way, a chart was developed of how children should grow with good health practices and healthy environmental conditions. Although recreating such a study for children with $\mathrm{CP}$ would be challenging, a similar chart might be created by identifying a group of children with CP in "good health" and then describing their growth. Such a chart should utilize only reliable measures of growth, as supported by existing studies.

Currently, there is little data to guide clinicians regarding what constitutes ideal, or even adequate, growth and nutritional status in children with CP. Clinicians must make judgments based on clinical impression and plotting of children on standard growth charts [Stevenson, 2007]. The data linking skinfold thickness with health and participation [Samson-Fang et al., 2002] suggest that skinfold thickness can help with clinical decision-making. 


\section{MANAGEMENT OF GROWTH AND NUTRITION}

\section{Treatment of Malnutrition}

Once children are identified as being malnourished or at risk of malnutrition, treatment is straightforward, although it may be difficult. The first step is interpretation of nutritional status, based on the history, physical examination, diet history, and anthropometry. Next, establishing a target weight or a target skinfold thickness is clinically useful. The target weight can be determined, empirically, as the weight at which triceps and/or subscapular skinfolds are between the 10th and 50th percentile. With this as a goal, one then works to maximize the child's oral intake. This may involve adjusting textures, optimizing caloric intake, altering postural supports, treating medical problems (such as constipation and gastroesophageal reflux), increasing the frequency of feedings, adding high calorie oral supplements, and ensuring adequate protein and micronutrients in the diet. Monitoring of the response to nutritional supplementation should include a measure of weight gain, linear growth (e.g., knee height), and skinfold thickness.

To guide nutritional management, it is important to estimate caloric needs using a reliable method. The WHO equations for predicting basal metabolic rate from body weight [Stevenson and Meyers, 2001] are easy to use and appear to closely estimate resting energy expenditure in children with CP [Bandini et al., 1991; Stallings et al., 1996]. This is especially true in children with $\mathrm{CP}$ who have adequate fat stores but may underestimate calorie needs in those with low fat stores. The United States Recommended Dietary Allowances [National Research Council, Food and Nutrition Board, 1989] are used frequently by dieticians in the United States but they seem to overestimate caloric needs [Stallings et al., 1996].

Once calorie needs have been estimated, the intake of the child must be adjusted to support optimal growth. If a child is taking only oral feedings, parents and caretakers are encouraged to add fats to food, to add dry milk powder or cream to foods, and to offer oral supplements. Many acceptable, nutritionally balanced commercial supplements are available, either in juice or milk base.

If nutritional status remains poor despite the best oral intake and medical management, then supplemental tube feedings become necessary. Tube feedings have become an accepted standard of care for children with severe disabilities [Sullivan, 1992; Eltumi and Sullivan, 1997]. Tube feedings can be nasogastric (short-term supplementation) or via gastrostomy (long-term supplementation). Use of nasogastric feeding may be appropriate to allow nutritional rehabilitation or to ensure that a child can tolerate enteral feeding. Use of a nasogastric tube for long-term feeding is not practical in most instances. Frequently, children with $\mathrm{CP}$ require long-term tube-feedings. The decision to place a gastrostomy tube is often a difficult one for families and requires preparation, education, and discussion. In particular, parents may need to be reassured that, in most cases, the child may continue to eat by mouth without the pressure to orally consume all calories necessary for growth and energy.

Management of tube feedings should be tailored to the individual child. Children may be fed blended tube feedings of appropriate nutrients or an age appropriate commercial formula. Continued monitoring of growth will prevent overfeeding and obesity. Calories may need to be reduced to prevent excessive weight gain. Clinicians need to be aware that commercial formulas may not provide adequate balance of protein, calcium, vitamin $\mathrm{D}$, and other micronutrients when they are used in less that typical volumes for weight due to the lower energy needs of some children with immobility. These must be replaced by protein, vitamin, and mineral supplements to insure optimal growth and health. Since there is little specific information for micronutrient needs in children with disabilities, the recommended daily 
allowances of the USDA [National Research Council, Food and Nutrition Board, 1989] seem prudent.

\section{Gastrostomy Placement}

Successful treatment of malnutrition in children with severe disabilities often requires a feeding gastrostomy to supplement or replace oral feedings [Stevenson and Meyers, 2001; Sullivan, 1992; Samson-Fang et al., 2003]. Unfortunately, the placement of a gastrostomy in a child with $\mathrm{CP}$ does carry some risk, and parents are frequently reluctant to have a gastrostomy placed [Sullivan, 1992]. There has been some controversy regarding the need for anti-reflux procedures simultaneous with placement of a gastrostomy, but the need for fundoplication in these children has not been studied by clinical trial [Vernon-Roberts and Sullivan, 2007].

A recent review of the literature failed to show convincing evidence of the benefits of gastrostomy placement in children with severe motor impairments [Sleigh and Brocklehurst, 2004]. A subsequent clinical trial, however, has contributed to the evidence that placement of a gastrostomy and improving nutrition is, in fact, beneficial to both the child and the family. Sullivan and colleagues [Sullivan et al., 2005] report on a prospective longitudinal trial of gastrostomy feedings in a large cohort of children with severe CP. This study improves on older studies by enrolling a relatively large number of subjects in a prospective trial. They utilized reliable anthropometric measures as their primary outcome measure. Most importantly, the authors went beyond growth as the sole outcome measure and included indicators of health, reported hospitalizations, as an outcome. Despite the relatively short-term nature of this study (1-year follow-up), the authors demonstrated statistically significant and clinically important improvements in weight, length, and skinfold thicknesses, coupled with improvements in health and parental concern about health. In a companion study of the same cohort, the quality of life measures for caregivers were much improved at 6 months and by 12 months were no different from reference standards [Sullivan et al., 2004]. Despite concerns that gastrostomies might increase reflux-related respiratory illness (aspiration pneumonia), the cohort demonstrated a decrease in chest infections and no change in hospitalizations for pneumonia [Sullivan et al., 2006]. Although not randomized and blinded, these studies support the use of feeding gastrostomy and supplemental feedings in children with severe CP as a means of improving physical growth, general health, and family quality of life [Stevenson, 2005].

\section{Treatment of Low Bone Density}

Increasing bone density through medical treatment is an area of active research. A recent clinical trial showed striking increases in bone density after administration of IV bisphosphonate to osteopenic children with CP [Henderson et al., 2002b] and bisphosphonate treatment also appears to decrease fracture rate [Grissom and Harcke, 2003]. Other promising treatments (passive standing with and without vibration) are currently under investigation as well [Caulton et al., 2004]. A recent pilot study by Ali et al. [2007] compared bone density in osteopenic children with CP treated with GH therapy at standard doses to that of untreated osteopenic children with $\mathrm{CP}$. The investigators found that the treatment group had an increase in spinal bone density that was statistically significant [Ali et al., 2007]. One concern about this finding is that it seems that spinal bone density is not well correlated with fracture risk in children with CP (bone density at the lateral femur may be more helpful). Further, there was no significant difference in quality of life measures or in fracture rate over the 18 months of this trial. It may be that the time period of the trial was too brief to detect differences, or possibly that the group was too small. Further work is needed to clarify the pathophysiology of low bone density in children with $\mathrm{CP}$ in order to inform clinical management for the prevention and treatment of fractures. 


\section{Other Treatments}

Other supplemental treatments have not been investigated systematically. For example, the potential role of GH therapy for improving growth in areas beyond bone growth needs further investigation. Thus far, only case reports and one pilot study regarding the use of GH in children with CP have been published [Coniglio and Stevenson, 1995; Coniglio et al., 1996; Shim et al., 2004; Ali et al., 2007]. On theoretical grounds, it seems likely that using GH in children with CP might improve lean muscle mass, muscle strength, bone density, and possibly physical functioning as it does in other groups of children [Hardin et al., 2005].

A controversial case report of growth attenuation in a child with static encephalopathy raises the issue that maximizing growth in children with developmental disabilities may not be ideal for families. Drs Gunther and Diekema describe the case of a patient with static encephalopathy, whose parents chose to pursue growth limiting therapy with hysterectomy followed by high dose estrogen for their daughter [Gunther and Diekema, 2006]. Caring for a child with severe motor and cognitive disabilities in the home is a challenge that may become more difficult as a child grows to adult size; in this case, the family and physicians strongly believed that keeping this child physically immature as well as small was in the child's best interests. Brosco and Feudtner, in a companion editorial, explore the inherent ethical concerns of growth attenuation [Brosco and Feudtner, 2006], but do not discuss the ample evidence that children with severe disabilities, such as CP, are smaller than their typically developing peers. Nor do they discuss emerging evidence that size may be linked to overall health. Regardless of ethical considerations, informed consent requires that parents be aware that, even without growth attenuating therapy, their children may not grow to an unmanageable size.

\section{SUMMARY AND IMPLICATIONS}

Children with CP frequently grow poorly. Sometimes, the poor growth is simply a manifestation of the underlying disability, and therefore does not require intervention. However, often the poor growth is a manifestation of malnutrition, endocrinopathy, or poor bone growth. Given the potential adverse effects of malnutrition and poor growth, it may be reasonable to address any alterable causes. The consensus among clinicians and researchers is that malnutrition in children with $\mathrm{CP}$ warrants treatment. Although this may seem obvious, there is limited scientific data to support the hypothesis that well-nourished children with disabilities are truly better off than malnourished children with disabilities. Prudence, clinical judgment, and (increasingly) results of scientific studies dictate that malnutrition and poor growth be treated; however, more data to support this stance are needed. Currently growth is defined quantitatively using body measurements, without clear links to functional status, general health, or quality of life. The body habitus that leads to optimal health and well-being remains undefined. Herein lies the critical need for future research. If the over-arching goal is to optimize function and quality of life for children with $\mathrm{CP}$, then future research must determine the range of growth and nutritional measurements that leads to optimal health and well-being.

\section{Acknowledgments}

Grant sponsor: National Center for Medical Rehabilitation Research; Grant number: K24-HD041504-01; Grant sponsor: Maternal and Child Health Bureau; Grant number: 4 T77MC00022-04-01.

\section{REFERENCES}

Ali O, Shim M, Fowler E, et al. Growth hormone therapy improves bone mineral density in children with cerebral palsy: a preliminary pilot study. J Clin Endocrin Metab 2007;92:932-937. 
Bandini LG, Schoeller DA, Fukagawa NK, et al. Body composition and energy expenditure in adolescents with CP or myelodysplasia. Pediatr Res 1991;29:70-77. [PubMed: 2000262]

Brosco JP, Feudtner C. Growth attenuation: a diminutive solution to a daunting problem. Arch Pediatr Adolesc Med 2006;160:1077-1078. [PubMed: 17018468]

Campanozzi A, Capano G, Miele E, et al. Impact of malnutrition on gastrointestinal disorders and gross motor abilities in children with cerebral palsy. Brain Dev 2007;29:25-29. [PubMed: 16843628]

Caulton JM, Ward KA, Alsop CW, et al. A randomised controlled trial of standing programme on bone mineral density in nonambulant children with cerebral palsy. Arch Dis Child 2004;89:131-135. [PubMed: 14736627]

Centers for Disease Control and Prevention. National Institute on Disability and Rehabilitation Research. U.S. Department of Education. Healthy People 2010. Department of Health and Human Services; 1999.

Chandra RK, Kumari S. Nutrition and immunity: an overview. J Nutr 1994;124:1433S-1435S. [PubMed: 8064398]

Chumlea WC, Guo SS, Steinbaugh ML. Prediction of stature from knee height for black and white adults and children with application to mobility-impaired or handicapped persons. J Am Diet Assoc 1994;94:1385-1388. [PubMed: 7963188]

Coniglio SJ, Stevenson RD. Growth hormone deficiency in two children with cerebral palsy. Dev Med Child Neurol 1995;37:1013-1015. [PubMed: 8566448]

Coniglio SJ, Stevenson RD, Rogol AD. Apparent growth hormone deficiency in children with cerebral palsy. Dev Med Child Neurol 1996;38:797-804. [PubMed: 8810711]

Cronk C, Crocker AC, Pueschel SM, et al. Growth charts for children with Down Syndrome: 1 month to 18 years of age. Pediatrics 1988;81:102-110. [PubMed: 2962062]

Day S, Strauss D, Vachon P, et al. Growth patterns in a population of children and adolescents with cerebral palsy. Dev Med Child Neurol 2007;49:167-171. [PubMed: 17355471]

De Vivo DC, Bohan TP, Coulter DL, et al. L-Carnitine supplementation in childhood epilepsy: current perspectives. Epilepsia 1998;39:1216-1225. [PubMed: 9821988]

Eltumi M, Sullivan PB. Nutritional management of the disabled child: the role of percutaneous endoscopic gastrostomy. Dev Med Child Neurol 1997;39:66-68. [Review] [33 refs]. [PubMed: 9003733]

Engsner G, Habre D, Sjogren I, et al. Brain growth in children with kwashiorkor. Acta Paediatr Scand 1974;63:687-694. [PubMed: 4547150]

Frisancho RA. New norms of upper limb fat and muscle areas for assessment of nutritional status. Am J Clin Nutr 1981;34:2540-2545. [PubMed: 6975564]

Fung EB, Samson-Fang L, Stallings VA, et al. Feeding dysfunction is associated with poor growth and health status in children with CP. J Am Diet Assoc 2002;102:361-373. [PubMed: 11902369]

Grantham-Mcgregor S, Powell C, Walder S, et al. Nutritional supplementation, psychosocial stimulation, and mental development of stunted children: the Jamaican study. Lancet 1991;338:1-5. [PubMed: 1676083]

Graves P. Nutrition and infant behavior: a replication study in the Katmandu Valley, Nepal. Am J Clin Nutr 1978;31:541-551. [PubMed: 629222]

Grissom LE, Harcke HT. Radiographic features of bisphosphonate therapy in pediatric patients. Pediatr Radiol 2003;33:226-229. [PubMed: 12709749]

Gunther DF, Diekema DS. Attenuating growth in children with profound developmental disability: a new approach to an old dilemma. Arch Pediatr Adolesc Med 2006;160:1013-1017. [PubMed: 17018459]

Harcke HT, Taylor A, Bachrach S, et al. Lateral femoral scan: an alternative method for assessing bone mineral density in children with cerebral palsy. Pediatr Radiol 1998;28:241-246. [PubMed: 9545479]

Hardin DS, Rice J, Ahn C, et al. Growth hormone treatment enhances nutrition and growth in children with cystic fibrosis receiving enteral nutrition. J Pediatr 2005;146:324-328. [see comment]. [PubMed: 15756212]

Henderson RC. Bone density and other possible predictors of fracture risk in children and adolescents with spastic quadriplegia. Dev Med Child Neurol 1997a;39:224-227. [PubMed: 9183259] 
Henderson RC. The correlation between dual-energy X-ray absorptiometry measures of bone density in the proximal femur and lumbar spine of children. Skeletal Radiol 1997b;26:544-547. [PubMed: 9342815]

Henderson RC, Grossberg RI, Matuszewski J, et al. Growth and nutritional status in residential center versus home-living children and adolescents with quadriplegic cerebral palsy. J Pediatr 2007;151:161-166. [PubMed: 17643769]

Henderson RC, Kairalla J, Abbas A, et al. Predicting low bone density in children and young adults with quadriplegic cerebral palsy. Dev Med Child Neurol 2004;46:416-419. [PubMed: 15174534]

Henderson RC, Kairalla JA, Barrington JW, et al. Longitudinal changes in bone density in children and adolescents with moderate to severe cerebral palsy. J Pediatr 2005;146:769-775. [PubMed: 15973316]

Henderson RC, Lark RK, Gurka MJ, et al. Bone density and metabolism in children and adolescents with moderate to severe cerebral palsy. Pediatrics 2002a;110:e5. [PubMed: 12093986]

Henderson RC, Lark RK, Kecskemethy HH, et al. Bisphosphonates to treat osteopenia in children with quadriplegic cerebral palsy: a randomized, placebo-controlled clinical trial. J Pediatr 2002b;141:644651. [PubMed: 12410192]

Henderson RC, Lark RK, Newman JE, et al. Pediatric reference data for dual X-ray absorptiometric measures of normal bone density in the distal femur. AJR Am J Roentgenol 2002c;178:439-443. [PubMed: 11804914]

Henderson RC, Lark RK, Renner JB, et al. Dual X-ray absorptiometry assessment of body composition in children with altered body posture. J Clin Densitom 2001;4:325-335. [PubMed: 11748337]

Henderson RC, Lin PP, Greene WB. Bone-mineral density in children and adolescents who have spastic cerebral palsy. J Bone Joint Surg Am 1995;77:1671-1681. [PubMed: 7593076]

Hillesund E, Skranes J, Trygg KU, et al. Micronutrient status in children with cerebral palsy. Acta Paediatr 2007;96:1195-1198. [PubMed: 17655620]

Jevsevar DS, Karlin LI. The relationship between preoperative nutritional status and complications after an operation for scoliosis in patients who have cerebral palsy. J Bone Joint Surg Am 1993;75:880884. [published erratum appears in J Bone Joint Surg Am 1993 Aug; 75(8):1256]. [PubMed: 8314827]

Kelly SM, Rosa A, Field S, et al. Inspiratory muscle strength and body composition in patients receiving total parenteral nutrition therapy. Am Rev Respir Dis 1984;130:33-37. [PubMed: 6430137]

King W, Levin R, Schmidt R, et al. Prevalence of reduced bone mass in children and adults with spastic quadriplegia. Dev Med Child Neurol 2003;45:12-16. [PubMed: 12549750]

Krick J, Murphy-Miller P, Zeger S, et al. Pattern of growth in children with cerebral palsy. J Am Diet Assoc 1996;96:680-685. [PubMed: 8675911]

Lark RK, Williams CL, Stadler D, et al. Serum prealbumin and albumin concentrations do not reflect nutritional state in children with cerebral palsy. J Pediatr 2005;147:695-697. [PubMed: 16291366]

Lewis D, Khoshoo V, Pencharz PB, et al. Impact of nutritional rehabilitation on gastroesophageal reflux in neurologically impaired children. J Pediatr Surg 1994;29:167-170. [PubMed: 7513758]

Liu J, Raine A, Venables PH, et al. Malnutrition at age 3 years and lower cognitive ability at age 11 years: independence from psychosocial adversity. Arch Pediatr Adolesc Med 2003;157:593-600. [PubMed: 12796242]

Liu LF, Roberts R, Moyer-Mileur L, et al. Determination of body composition in children with cerebral palsy: bioelectrical impedance analysis and anthropometry vs dual-energy x-ray absorptiometry. J Am Diet Assoc 2005;105:794-797. [PubMed: 15883558]

Lohman, TG.; Roche, AF.; Martorell, R. Anthropometric standardization reference manual. Human Kinetics Books; Champaign: 1988.

Lundberg A. Oxygen consumption in relation to work load in students with cerebral palsy. J Appl Physiol 1976;40:873-875. [PubMed: 931924]

McCoy AA, Fox MA, Schaubel DE, et al. Weight gain in children with hypertonia of cerebral origin receiving intrathecal baclofen therapy. Arch Phys Med Rehabil 2006;87:1503-1508. [PubMed: 17084127]

Meyer-Heim AD, Khan Y. Nail dystrophy-a clinical sign of malnutrition in the disabled child. Eur J Pediatr 2004;163:567-568. [PubMed: 15243807] 
Myrelid A, Gustafsson J, Ollars B, et al. Growth charts for Down's syndrome from birth to 18 years of age. Arch Dis Child 2002;87:97-103. [PubMed: 12138052]

National Research Council. Food and Nutrition Board. Recommended dietary allowances. National Academy of Science; Washington, DC: 1989.

Patrick J, Gisel E. Nutrition for the feeding impaired child. J Neuro Rehab 1990;4:115-119.

Roberts CD, Vogtle L, Stevenson RD. Effect of hemiplegia on skeletal maturation. J Pediatr 1994;125 (5 Part 1):824-828. [PubMed: 7965443]

Rongen-Westerlaken C, Corel L, van den BJ, et al. Reference values for height, height velocity and weight in Turner's syndrome. Swedish Study Group for GH Treatment. Acta Paediatr 1997;86:937-942. [PubMed: 9343271]

Rosenbaum P, Paneth N, Leviton A, et al. A report: the definition and classification of CP April 2006. Dev Med Child Neurol Suppl 2007;109:8-14. [PubMed: 17370477]

Samson-Fang L, Butler C, O'Donnell M, et al. Effects of gastrostomy feeding in children with CP: an AACPDM evidence report. Dev Med Child Neurol 2003;45:415-426. [Review] [35 refs]. [PubMed: 12785443]

Samson-Fang L, Fung E, Stallings VA, et al. Relationship of nutritional status to health and societal participation in children with cerebral palsy. J Pediatr 2002;141:637-643. [PubMed: 12410191]

Samson-Fang L, Stevenson RD. Linear growth velocity in children with cerebral palsy. Dev Med Child Neurol 1998;40:689-692. [PubMed: 9851238]

Samson-Fang LJ, Stevenson RD. Identification of malnutrition in children with cerebral palsy: poor performance of weight-for-height centiles. Dev Med Child Neurol 2000;42:162-168. [PubMed: 10755455]

Shim ML, Moshang T Jr, Oppenheim WL, et al. Is treatment with growth hormone effective in children with cerebral palsy? Dev Med Child Neurol 2004;46:569-571. [PubMed: 15287249]

Slaughter MH, Lohman TG, Boileau RA, et al. Skinfold equations for estimation of body fatness in children and youth. Hum Biol 1988;60:709-723. [PubMed: 3224965]

Sleigh G, Brocklehurst P. Gastrostomy feeding in cerebral palsy: a systematic review. Arch Dis Child 2004;89:534-539. [Review] [86 refs]. [PubMed: 15155398]

Smart J. Malnutrition, learning, and behavior: 25 years on from the MIT symposium. Proc Nutr Soc 1993;52:189-199. [PubMed: 8493264]

Spender QW, Cronk CE, Charney EB, et al. Assessment of linear growth of children in cerebral palsy: use of alternative measures to height or length. Dev Med Child Neurol 1989;31:206-214. [PubMed: 2737373]

Stallings VA, Charney EB, Davies JC, et al. Nutritional status and growth of children with diplegic or hemiplegic cerebral palsy. Dev Med Child Neurol 1993a;35:997-1006. [PubMed: 8224567]

Stallings VA, Charney EB, Davies JC, et al. Nutrition-related growth failure of children with quadriplegic cerebral palsy. Dev Med Child Neurol 1993b;35:126-138. [PubMed: 8444326]

Stallings VA, Cronk CE, Zemel BS, et al. Body compositionin children with spastic quadriplegic cerebral palsy. J Pediatr 1995;126:833-839. [PubMed: 7752019]

Stallings VA, Zemel BS, Davies JC, et al. Energy expenditure of children and adolescents with severe disabilities: a cerebral palsy model. Am J Clin Nutr 1996;64:627-634. [PubMed: 8839510]

Stevenson R. Beyond growth: gastrostomy feeding in children with cerebral palsy. Dev Med Child Neurol 2005;47:76. [PubMed: 15707229]

Stevenson RD. Use of segmental measures to estimate stature in children with cerebral palsy. Arch Pediatr Adolesc Med 1995;149:658-662. [PubMed: 7767422]

Stevenson RD. Measurement of growth in children with developmental disabilities. Dev Med Child Neurol 1996;38:855-860. [PubMed: 8810718]

Stevenson, RD. Nutrition and growth. In: Accardo, PJ., editor. Capute and Accardo's neurodevelopmental disabilities in infancy and childhood. Brookes; Baltimore: 2007.

Stevenson RD, Conaway M, Barrington JW, et al. Fracture rate in children with cerebral palsy. Pediatr Rehabil 2006a;9:396-403. [PubMed: 17111566]

Stevenson RD, Conaway M, Chumlea WC, et al. Growth and health in children with moderate-to-severe cerebral palsy. Pediatrics 2006b;118:1010-1018. [PubMed: 16950992] 
Stevenson RD, Hayes RP, Cater LV, et al. Clinical correlates of linear growth in children with cerebral palsy. Dev Med Child Neurol 1994;36:135-142. [PubMed: 8132124]

Stevenson, RD.; Meyers, R. Nutrition in the child with disabilities. In: Grimble, GK.; Preedy, VR.; Watson, RR., editors. Nutrition and the infant: practice and procedures. Greenwich Medical Media, Ltd.; London: 2001. p. 267-275.

Stevenson RD, Roberts CD, Vogtle L. The effects of non-nutritional factors on growth in cerebral palsy. Dev Med Child Neurol 1995;37:124-130. [PubMed: 7851668]

Strauss D, Shavelle R, Reynolds R, et al. Survival in cerebral palsy in the last 20 years: signs of improvement? Dev Med Child Neurol 2007;49:86-92. [see comment]. [PubMed: 17253993]

Styles ME, Cole TJ, Dennis J, et al. New cross sectional stature, weight, and head circumference references for Down's syndrome in the UK and Republic of Ireland. Arch Dis Child 2002;87:104108. [PubMed: 12138054]

Sullivan PB. Gastrostomy and the disabled child. Dev Med Child Neurol 1992;34:547-555. [PubMed: 1612216]

Sullivan PB, Juszczak E, Bachlet AM, et al. Impact of gastrostomy tube feeding on the quality of life of carers of children with cerebral palsy. Dev Med Child Neurol 2004;46:796-800. [PubMed: 15581151]

Sullivan PB, Juszczak E, Bachlet AM, et al. Gastrostomy tube feeding in children with cerebral palsy: a prospective, longitudinal study. Dev Med Child Neurol 2005;47:77-85. [PubMed: 15707230]

Sullivan PB, Morrice JS, Vernon-Roberts A, et al. Does gastrostomy tube feeding in children with cerebral palsy increase the risk of respiratory morbidity? Arch Dis Child 2006;91:478-482. [see comment]. [PubMed: 16446283]

Tobis JS, Saturen P, Larios G, et al. Study of growth patterns in cerebral palsy. Arch Phys Med Rehabil 1961;42:475-481. [PubMed: 13777130]

Vernon-Roberts A, Sullivan PB. Fundoplication versus post-operative medication for gastro-oesophageal reflux in children with neurological impairment undergoing gastrostomy. Cochrane Database Syst Rev 2007:006151.

Viart P. Hemodynamic findings in severe protein-calorie malnutrition. Am J Clin Nutr 1977;30:334-348. [PubMed: 402806]

Viart P. Hemodynamic findings during treatment of protein calorie malnutrition. Am J Clin Nutr 1978;31:911-926. [PubMed: 96686]

Viteri, FE. Protein energy malnutrition. In: Viteri, FE.; Walker, AW.; Durie, PR., et al., editors. Pediatric gastrointestinal diseases. B.C. Decker; Philadelphia: 1991. p. 1596-1611.

Weber TR. A prospective analysis of factors influencing outcome after fundoplication. J Pediatr Surg 1995;30:1061-1064. [PubMed: 7472933]

WHO Multicentre Growth Reference Study Group. WHO Child Growth Standards based on length/ height, weight and age. Acta Paediatr Suppl 2006;450:76-85. [PubMed: 16817681]

Worley G, Houlihan CM, Herman-Giddens ME, et al. Secondary sexual characteristics in children with cerebral palsy and moderate to severe motor impairment: a cross-sectional survey. Pediatrics 2002;110:897-902. [PubMed: 12415027]

Yeargin-Allsop M, Braun KVN, Doernberg NS, Benedict RE, Kirby RS, Durkin MS. Prevalence of cerebral palsy in 8-year-old children in three areas of the United States in 2002: a multisite collaboration. Pediatrics 2008;121:547-554. [PubMed: 18310204] 